\title{
PLANO DIRETOR E PATRIMÔNIO HISTÓRICO: ANÁLISE A PARTIR DA CONSTITUIÇÃO FEDERAL DE 1988 E DO ESTATUTO DA CIDADE
}

\author{
MASTER PLAN AND HERITAGE: ANALYSIS FROM THE 1988 FEDERAL CONSTITUTION \\ AND THE CITY STATUTE
}

\author{
Janaína Rigo Santin ${ }^{1}$ \\ Mariana Mattei Santos ${ }^{2}$
}

\section{Resumo}

O presente trabalho propõe uma reflexão acerca das questões ligadas à evolução e à consolidação das cidades no que tange ao desenvolvimento da consciência de preservação do patrimônio histórico. Procurar-se-á compreender, pelo método dialético, quais as são as competências responsáveis pela imposição dessas tendências e a justificativa da sua importância ante a sociedade contemporânea, bem como enfocar o valor da participação popular na elaboração de preceitos que beneficiem diretamente a comunidade e que incidirão nas gerações futuras, por meio do cultivo das heranças edificadas na cidade pelas gerações passadas. Percebe-se que com a legislação urbanística atual foram dados os primeiros passos para a descoberta da consciência patrimonial, da gestão democrática municipal e da elaboração participativa das leis e políticas urbanas relativas ao meio ambiente urbano. Resta consolidá-los para as presentes e futuras gerações.

Palavras-chave: Cidade. Plano diretor. Patrimônio histórico. Participação popular. Urbanismo.

\begin{abstract}
The purpose of this study is to make an exhibition of conceptualizations about the issues related to evolution and consolidation of cities and the development of awareness of preservation of the public through the temporal dialectic. In parallel, it will seek to understand what skills are responsible for enforcement of these trends and the justification of its importance in the face of contemporary society. The value of public participation in drafting ordinances that directly benefit the community and that will influence future generations, through the cultivation of inheritances entered the city by past generations. With the current planning legislation were the first steps to ascertain the equity consciousness, the municipal democratic management and participatory development of urban laws and policies relating to the urban environment. It remains to consolidate them for present and future generations.
\end{abstract}

Keywords: City. Master plan. Heritage. Popular participation. Urbanism.

\footnotetext{
1 Pós-Doutorado em Direito Administrativo pela Universidade de Lisboa, Portugal, com bolsa CAPES. Professora Titular I da Universidade de Passo Fundo, nas disciplinas de direito municipal, direito urbanístico e direito das obrigações. Professora da Universidade de Caxias do Sul, das disciplinas de direito administrativo e direito constitucional. Faz parte do corpo docente permanente do Mestrado em Direito e do Mestrado e Doutorado em História da Universidade de Passo Fundo. Professora da Graduação e Pós-Graduação lato sensu da Faculdade de Direito da Universidade de Passo Fundo. Professora convidada do Mestrado em Ciências Jurídicas-Econômicas e Desenvolvimento e do Mestrado em Governação e Gestão Pública da Universidade Agostinho Neto, em Luanda, Angola-África. E-mail: janainars@upf.br

2 Mestre em História da Universidade de Passo Fundo-RS, com bolsa Fapergs. Professora da Escola de Arquitetura e Urbanismo do Instituto Meridional - IMED. E-mail: mariana.arq@live.com
} 


\section{INTRODUÇÃO: PLANEJAR CIDADES NO TEMPO}

Os esforços para conter o avanço da depredação do patrimônio histórico das cidades brasileiras são imensuráveis, tendo em vista a dificuldade na abordagem do tema e na conscientização social da relevância da preservação do patrimônio para a manutenção da memória e da identidade daquele grupo social. A conservação de edificações consideradas importantes para a história sociocultural de uma comunidade divide opiniões, sejam elas de propriedade pública ou privada. Até o advento da Constituição de 1988 esses esforços eram muitas vezes espontâneos por parte da administração pública, defendendo interesses nem sempre coletivos pró-conservação e até mesmo pela falta de diretrizes que orientassem procedimentos adequados de preservação e restauro de edificações históricas.

O intuito deste trabalho é fazer uma reflexão acerca da evolução das questões ligadas ao planejamento urbano até a Constituição Federal de 1988 e a elaboração dos Planos Diretores Municipais capazes de contemplar a preocupação com a preservação do Patrimônio Histórico, no que tange ao âmbito político administrativo, bem como a influência das relações de poder e o resgate da cidadania em âmbito municipal.

Para tanto, será realizada uma análise sobre a evolução do urbanismo e das noções sobre proteção do patrimônio, com vistas a se chegar à atual legislação urbanística brasileira, posta na Constituição Federal de 1988 e no Estatuto da Cidade (Lei Federal 10.257/2001).

\section{AS PRÁTICAS URBANÍSTICAS}

O urbanismo, como disciplina, surge da necessidade de se estabelecerem normas para as relações e as atividades humanas em um meio urbano. $O$ termo, hoje amplamente utilizado, deriva da palavra latina Urb, a qual o engenheiro e arquiteto catalão Ildefonso Cerda ${ }^{3}$ referia em seus estudos para designar uma disciplina relacionada à organização das cidades (HAROUEL, 1990). urbanismo moderno, como hoje é conhecido, surge no final do século XIX. Mas a arte urbana, tal como se referia Harouel $(1990$, p. 7) é um fato que se faz presente desde a antiguidade.

Conforme é relatado por Harouel (1990, p. 11), a noção de urbanismo na Grécia antiga observa-se na tentativa de organização da polis, termo utilizado para designar suas cidades-estado

\footnotetext{
${ }^{3}$ Ildefonso Cerda y Sunyer (1815 - 1816) foi um desenhista, arquiteto e matemático catalão que mais tarde tornar-se-ia engenheiro de caminhos. Após trabalhar em diversos projetos de construção de estradas passa a dedicar-se aos estudos das cidades. Seus estudos são considerados por muitos a gênese do urbanismo moderno (GONSALES, 2005).
} 
e que compreendia também os campos, onde também viviam os seus cidadãos. Já no império romano, que também recebera grande influência da cultura grega, existia uma preocupação metódica em organizar a cidade em eixos ortogonais, embora houvesse a noção de se adaptar tal metodologia à natureza de cada lugar. À parte este preciosismo formal romano, era possível verificar o anseio desta sociedade pela qualidade de vida, e isso se manifesta por meio dos equipamentos públicos existentes àquela época, como teatros, circos, anfiteatros, termas, os quais eram organizados em uma praça, o que ainda hoje é possível de ser constatado mediante o contato com suas ruínas (HAROUEL, 1990).

Acompanhando progressivamente a evolução na formação das comunidades constata-se que, no período da idade média, a multiplicação de cidades pela Europa a partir do século XI conforma-se principalmente em torno de abadias ou de castelos, com pouco ou ínfimo desenvolvimento econômico, o qual se dava principalmente mediante as atividades dos artesãos e dos comerciantes. Vale lembrar que a insegurança vivida pela sociedade do medievo fez com que o crescimento urbano estagnasse ou mesmo retrocedesse, o que corrobora para que se conclua que a igreja foi a principal instituição responsável pela manutenção das cidades nessa época. Diferentemente das linhas retas romanas, a cidade medieval é orgânica, irregular e fechada por muralhas. Nestas cidades, paralelamente ao crescimento populacional acentuado, estão os problemas de salubridade e higiene dali decorrentes e que não eram previstos (HAROUEL, 1990, p. 35).

O planejamento urbano como estudo técnico começa a se apresentar de forma elementar no período compreendido pelo movimento renascentista. Surgem os primeiros tratados da arte de construir, entre eles a "De Re Aedificatoria", de Leon Battista Alberti ${ }^{4}$, o qual ainda é uma referência frequentemente empregada em pesquisas acadêmicas e estudos do espaço urbano e de edificações (GONSALES, 2005). Nesta fase, observa-se a introdução da perspectiva tanto nos desenhos como na própria disposição dos espaços edificados. Ordem e racionalidade na arte e arquitetura eram condição fundamental para se obter um bom resultado estético e funcional. 0 Renascimento produziu material técnico e intelectual que balizaria os estudos urbanos dos

\footnotetext{
${ }^{4}$ Nascido no início do século XV foi um estudioso ferrenho dos monumentos italianos e se dedicou a elaborar tratados sobre arquitetura e estética das cidades. Entre outras atividades, foi consultor de arquitetura da Santa Sé, para a qual trabalhou por muito tempo como abreviador apostólico. Era próximo de grandes Humanistas e frequentava o círculo de Brunelleschi. Só foi assumir plenamente seu ofício de arquiteto nas duas últimas décadas de vida. Algumas de suas obras arquitetônicas mais conhecidas são o Palazzo Ruccelai e fachada de Santa Maria Novela. Mais informações em Babel textos de arquitetura e urbanismo. Para maiores informações ver (ZANCHETTA, 2014).
} 
períodos seguintes, a começar pelo Barroco, que por força da religião católica apostólica romana, em especial mediante o esforço de papas como Sixto $V$, traçaria vias que uniriam pontos focais, entre eles igrejas, praças e belvederes, garantindo importância e visibilidade para estes monumentos (FAZIO; MOFFET; WODEHOUSE, 2011, p. 362).

Na sequência chega-se à metade do século XIX, que serviu de palco para a modernização de grandes cidades pelo mundo ocidental. A cidade de Londres já era servida por largas avenidas e parques e, também, já havia contido com sucesso os seus problemas com epidemias, as quais ocorriam por conta da insalubridade presente nas ruas e habitações. Por sua vez, na França, o Barão de Haussmann, prefeito do Sena, obteve a autorização para promover uma reforma drástica em Paris (HAROUEL, 1990, p. 113). Seu plano rasgou a cidade em vários eixos, criando os famosos bulevares, eliminando edificações remanescentes do período medieval e também as vielas, usadas estrategicamente às barricadas das revoluções civis da primeira metade do século XIX. Eram promovidos, concomitantemente, o saneamento da cidade com serviço de esgoto, gás encanado, abastecimento de água tratada e, principalmente do ponto de vista de Haussmann, o embelezamento (GONSALES, 2005). Nesse plano, destaca-se o cuidado em se preservar alguns monumentos importantes da cidade, com a preocupação de evidenciá-los a partir da criação de parques em seu entorno.

Com a experiência bem-sucedida de Haussmann, o engenheiro Ildefonso Cerda projetou o plano para ampliação da cidade de Barcelona. Sua expansão era restrita devido à muralha medieval que a circunscrevia, mas o plano previa a derrubada deste elemento, que era considerado o grande obstáculo ao crescimento da capital catalã (GONSALES, 2005). Por consequência do projeto, a cidade teve seu tamanho ampliado em progressivamente. As características estruturais e estéticas em Barcelona eram muito parecidas com as do plano de Hausmann, porém, aqui, Cerda não elimina a cidade medieval, apenas a neutraliza. Além disso, o urbanista catalão, diferentemente do prefeito parisiense, teve a preocupação de criar espaços de recreação para a comunidade e não apenas praças e passeios públicos, que objetivavam essencialmente o aspecto formal (GONSALES, 2005).

Chega o século XX e novos conceitos e teorias sobre o espaço urbano vão sendo delineados e seriamente discutidos em um movimento que logo se faria conhecido pela alcunha de CIAM (Congresso Internacional de Arquitetura Moderna). Os CIAM tiveram sua fundação em 1928, em La Sarraz, na Suíça e até 1956 passaram por diferentes países para reunirem-se em assembleias de trabalho, fomentando a opinião pública e instigando os profissionais para uma nova ideologia que 
seria perpetuada pela Carta de Atenas, 1933, redigida pelo arquiteto franco-suíço Le Courbusier (2000, p. 14).

Para Le Courbusier (2000, p. 14), os urbanistas que se apresentavam até a primeira metade do século XX eram demasiadamente retrospectivos, "museográficos", repetidores e absorvidos por ornamentos e representações recriadas no que se denomina a arquitetura historicista. Criticava intensamente o modelo de urbanismo europeu do século XIX, referindo-se a ele como "nefasto", com suas construções em cima da calçada, o que era totalmente contrário ao seu ideal.

A Carta de Atenas expressa em seu primeiro item geral que a cidade seria apenas um componente do todo econômico, social e político que configuraria o plano regional. O diagnóstico de que os recortes administrativos e geográficos, na maioria das vezes, não eram condizentes, levava a crer que essa condição não era favorável a uma gestão administrativa eficaz. Também foi registrado na Carta que não se podem ignorar fatores como a geografia e os elementos construtivos de cada região. Neste sentido, a conclusão que chegariam os urbanistas a seguir era de que as vias de comunicação eram o elemento fundamental para que os dispositivos urbanos pudessem desempenhar efetivamente seu papel (LE CORBUSIER, 1993, p. 1).

Este registro dos CIAM foi inovador para sua época, ao tratar de conceitos de ordem fisiológica e psicológica e da conciliação dos princípios individuais e coletivos, os quais devem reger a vida humana em uma cidade. A preocupação com a incidência do sol nas habitações, a necessidade de espaços abertos, de salubridade e a influência da natureza sobre a vida das pessoas é uma constante para os arquitetos modernistas, que também defendem o entendimento de que as questões da religião e da geografia são relevantes na expressão de cada sociedade.

No que se refere ao patrimônio histórico, o Congresso Internacional de Arquitetura Moderna (CIAM) promulgou a ideia de que edificações exemplares do passado deveriam ser preservadas a título de documentação, desde que sua a permanência não se sobrepusesse ao bemestar da sociedade a que pertenciam. Sempre que possível, os prédios históricos deveriam ter uma existência útil, todo o resto deveria ser eliminado, ao que se acrescenta a carta: "Convém escolher com sabedoria o que deve ser respeitado" (LE CORBUSIER, 1993, p. 25-26). Aqui, é importante ressaltar a preocupação que se tinha em restaurar a salubridade das cidades, de modo que, para aquele contexto, preservar determinados conjuntos de edificações e bairros históricos quando não úteis ao ideal anteriormente indicado significava cultivar a estrutura de promiscuidade, de falta de higiene e de miséria que eles, por vezes, acolhiam. 
Desse modo, patrimônio histórico, para o círculo de profissionais do movimento moderno nas primeiras décadas do século XX, era, sem dúvida, um tema relevante, mas com muitos pontos conflitantes que deveriam ser discutidos com critério, racionalidade e um certo distanciamento, levando-se em conta a carga afetiva que pode o implicar.

\section{O PATRIMÔNIO HISTÓRICO E A IDENTIDADE DAS CIDADES}

Para um bom entendimento acerca do tema em destaque é importante ponderar algumas definições. Conforme a autora Françoise Choay, patrimônio histórico é uma expressão utilizada para designar "um bem destinado ao usufruto de uma comunidade [...], constituído pela acumulação contínua de uma diversidade de objetos que se congregam por seu passado comum [...]" (CHOAY, 2001, p. 11). Para complementar este pensamento, Fonseca explica que "a ideia de posse coletiva como parte do exercício da cidadania inspirou a utilização do termo 'patrimônio' para designar o conjunto de bens de valor cultural que passaram a ser propriedade da nação, ou seja, do conjunto de todos os cidadãos" (2005, p. 58).

Entretanto, sabe-se que não só de objetos e edificações, de pedra e cal, é composto o acervo de itens qualificáveis como patrimônio histórico e cultural. Conforme o artigo 216 da Constituição Federal de 1988, também fazem parte os bens culturais de natureza imaterial, os quais têm a ver com as manifestações das práticas e esferas da vida de uma sociedade, tais como celebrações, músicas, danças, ciência, ou quaisquer formas de expressão que venham a ser referência de um grupo formador da sociedade e que sejam transmitidos de geração em geração.

E ainda, pode-se destacar a chancela da Paisagem Cultural, regulamentada pela portaria do Iphan № 127/2009, que está ligada diretamente à população que tem seu cotidiano baseado nas relações com o meio natural. Paisagem cultural é uma nova maneira de trabalhar o patrimônio cultural brasileiro, um termo cunhado pela UNESCO desde 1992, e é estabelecida através de personagens conhecidos da cultura brasileira como o gaúcho, o candango e o sertanejo, por exemplo, e seus lugares, respectivamente, os pampas, o cerrado e a caatinga. É um dispositivo que valoriza não só a própria paisagem, mas os habitantes que colaboraram para a sua configuração, com suas intervenções ou os valores por eles atribuídos (IPHAN, 2009, p. 13). Dessa forma, o Poder Público e sociedade civil têm em suas mãos mais um desafio, que é incrementar os Planos Diretores com legislação capaz de contemplar essas demandas, mas, acima de tudo, legitimar a participação de todo o cidadão, principalmente dos personagens que compõem cada cenário.

Assim, patrimônios Material e Imaterial, juntos, constituem o Patrimônio Histórico e Cultural de uma sociedade, o qual deve ser preservado com vistas a garantir com a identidade de 
um povo, tanto das presentes quanto das futuras gerações. Este artigo se restringe a trabalhar com o Patrimônio Material.

Nesse sentido, é necessário dizer que para qualificar uma edificação como bem histórico de interesse social é preciso o envolvimento de um grupo interdisciplinar que discuta, argumente e conclua conjuntamente, de forma criteriosa, pois arbitrar nestes casos não deve ser uma ação unilateral. Há vários fatores que precisam ser considerados para que não se defenda apenas pontos de vista intelectuais, particulares ou políticos. Os parâmetros para julgamento podem ser a qualidade arquitetônica da edificação, mas também podem estar apenas no repertório sociocultural que a edificação abriga.

No que tange aos aspectos tipológicos, para Piñón (2006, p. 152), as obras arquitetônicas e de arte em geral possuem dois elementos fundamentais, quais sejam: o sentido e a consistência. 0 primeiro refere-se à conexão material, cultural e histórica do objeto e seu exterior. Ele determina a posição do autor perante a história, o modo como ele interpreta a contemporaneidade com sua obra. Já a consistência trata das condições formais da obra, as relações interiores a ela, aos princípios de equilíbrio, coerência e intensidade, características que a qualificam para justificar sua permanência. São formas importantes presentes no cotidiano e no imaginário de pessoas por diversas gerações.

A história de uma comunidade pode ser revelada através de paredes, escadarias, objetos, monumentos contam histórias e, por que não dizer, eles podem ser a própria história, e o conjunto destes elementos ajuda a traçar a linha do tempo de uma sociedade. Ainda citando Piñón (2006, p.156), as obras de arquitetura e de arte são estabelecidas em uma esfera histórica determinada, a qual proporciona ao autor escolher inúmeros elementos teóricos, artísticos e materiais, que afetarão no sentido da obra e representam a consciência da historicidade da criação. Esta historicidade depende, terminantemente, do modo como o autor interpreta o sentido da história e decide atuar em relação a ele. Deste modo, Choay relata que

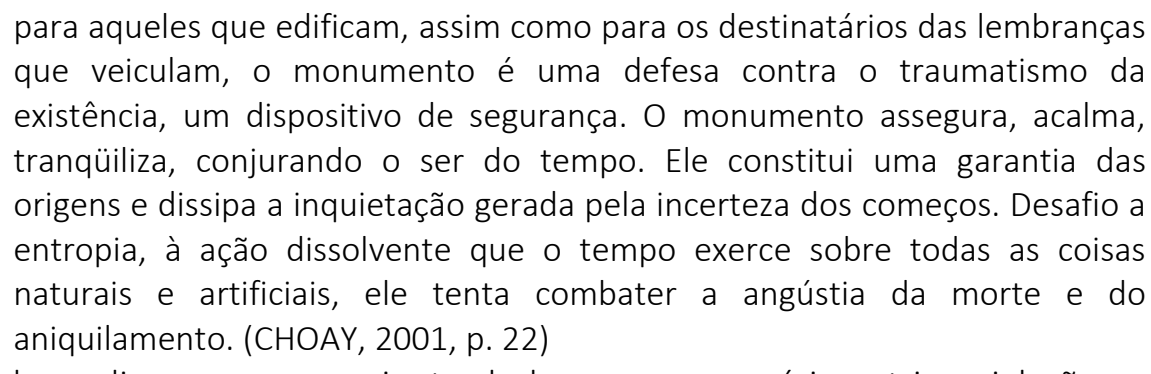

Sendo assim, pode-se dizer que um conjunto de bens com memória patrimonial não se constitui apenas de obras arquitetônicas icônicas e de monumentos criados deliberadamente, mas 
todo aquele espaço, edificação ou objeto que obteve em sua existência relação com acontecimentos significativos para determinada comunidade. Do contrário, este acervo estará contando apenas a história de elites, desconsiderando as experiências deixadas por uma grande parcela da sociedade. Entretanto, embora o equívoco desta afirmação seja evidente, esta foi a prática mais adotada na maioria dos centros urbanos brasileiros.

Além da decisão controversa pela escolha do que merece ser preservado, existe entre os defensores e teóricos deste tema algumas discordâncias quanto as formas de incentivo à preservação de edificações e sítios históricos, bem como a função que será atribuída aos bens. Essa discussão é determinante para o futuro e conservação patrimonial, pois em muitos casos será o único meio de fomento à sua permanência. Choay (2001, p. 15) acredita, por exemplo, que o crescimento recorde do turismo trouxe efeitos negativos ao patrimônio material, fazendo com que vários espaços fossem fechados à visitação por se encontrarem paulatinamente degradados. Essa inflação patrimonial também tem sido combatida e denunciada devido aos altos custos de manutenção, inconformidade aos fins contemporâneos e interrupção de outros grandes planos para a melhor disposição do espaço urbano.

Por outro lado, conforme entendem Silveira e Medaglia (2014), em muitos casos, o único incentivo à preservação patrimonial vem do mercado turístico. Assim, polêmica e discordância são reações comuns a temas que exigem decisões emergenciais, o que se conclui que para haver ações que evoquem a preservação do patrimônio material, por vezes é provável que se constatem atitudes heroicas e menos acadêmicas, deixadas corriqueiramente sob supervisão técnica apenas do profissional da arquitetura e urbanismo, ignorando todo um quadro técnico multidisciplinar que Ihe é indispensável bem como a apreciação de projetos pela comunidade. Também é possível que, mesmo imbuídas de boas intenções, sejam identificadas ações consideradas apelativas e desvirtuadas nesse âmbito. Tais ações podem corroborar, inclusive, para a descaracterização da edificação, do conjunto arquitetônico e/ou da paisagem. A reconstrução ou transferência de locus, simulando sítios para resgate de memória, identidade para incremento ao turismo sem a orientação técnica que lhe é pertinente podem facilmente causar distorção da realidade histórica do lugar tanto aos visitantes como aos moradores e futuras gerações. Para tanto, medidas que regulem e orientem qualquer ação que incida sobre o patrimônio são fundamentais, assim como sua fiscalização efetiva e constante. 


\section{A POLÍtICA URBANA NA CONSTITUIÇÃO FEDERAL DE 1988 E O ESTATUTO DA CIDADE: A SUSTENTABILIDADE E A PRESERVAÇÃO DO PATRIMÔNIO}

A necessidade da existência de dispositivos que regulamentem e fiscalizem o exercício de preservação patrimonial muda de enfoque quando se passa do campo acadêmico para o campo jurídico e político. Normalmente essa questão não é considerada pela sociedade em um primeiro momento devido ao seu distanciamento com o tema e, no caso dos cidadãos brasileiros, à existência de necessidades consideradas mais urgentes, como os direitos sociais, os quais, regularmente, não são atendidos pelo poder público. Contudo, o propósito humano de cultivar uma identidade, seja ela individual ou coletiva, e assim poder evoluir ou se reinventar a partir de uma trajetória pré-existente, iniciada pelos seus entes pregressos, é inexorável e tem reflexo nas ações dos indivíduos, como já retratado no texto.

O sentimento produzido pela ausência de uma edificação muitas vezes só é percebido com a mudança da paisagem urbana, ou seja, quando um número maior de prédios ou outros elementos edificados deixam de existir, provocando a perda de identidade coletiva do lugar. As cidades são dinâmicas e devem acompanhar o progresso, mas não pode perder suas referências de identidade. A cidade deve também contemplar seu processo evolutivo, sua história, os registros físicos daqueles que participaram da sua constituição.

No Brasil, a atenção com o patrimônio histórico material de uma forma sistematizada é recente. A falta de políticas urbanas preservacionistas, por um longo período, fez com que grande parte do acervo brasileiro sucumbisse à ação do descaso e dos interesses econômicos. Por esse motivo, é necessário identificar soluções eficazes que colaborem para a tarefa. Entretanto, a criação de leis não garante sua aplicação, mas coíbe ou dificulta ações arbitrárias e pode impor penalidades a quem as descumprir.

Para adequar-se às transformações, o poder público nas últimas décadas lançou mão de artifícios legais para coibir a devastação patrimonial e estimular o tombamento ${ }^{5}$ de patrimônios

\footnotetext{
${ }^{5}$ Tombamento: ação administrativa, em nível federal, estadual e municipal, realizada pelo poder público. Aplica-se a bens imóveis e móveis, de interesse ambiental e cultural como o caso de fotografias, obras bibliográficas, móveis, objetos de arte, obras de arquitetura e arte, cidades, regiões, florestas, cascatas, entre outros. É atribuído apenas para bens materiais que interessem à preservação da memória coletiva. Para o IPHAN, "O tombamento é o instrumento de reconhecimento e proteção do patrimônio nacional mais tradicional e foi instituído pelo Decreto-Lei no 25, de 30 de novembro de 1937. Sob a tutela do Iphan, os bens tombados se subdividem em bens móveis e imóveis, sendo que entre esses estão incluídos equipamentos urbanos e de infraestrutura, paisagens naturais, ruínas, jardins e parques históricos, terreiros e sítios arqueológicos. A proteção é uma das ações mais importantes referentes ao patrimônio de natureza material.
} 
públicos e privados. Conforme Santin (2007, p. 72) com o advento da Constituição de 1988, a autonomia financeira, política e administrativa concedida ao Município tirou-o da condição de subordinado ao poder central. Concomitante a este fato, o Poder Local, que no Brasil era vinculado, historicamente, ao coronelismo, ressurge com um novo caráter, passando às mãos do cidadão, que agora tem a possibilidade de agir junto ao poder público na formulação das tutelas jurídicas e políticas municipais.

E no intuito de empoderar o cidadão na busca por cidades mais sustentáveis, capazes de resguardar os interesses dos Munícipes e não apenas de seus representantes, foi editada a Lei n.으 10.257, de 11 de julho de 2001, denominada Estatuto da Cidade. Veio para regulamentar os artigos 182 e 183 da Constituição Federal de 1988, com vistas a traçar os objetivos da política urbana no Município e ditar novas diretrizes e princípios gerais para o processo de urbanização no Brasil. Destinada a desenvolver sustentavelmente as cidades brasileiras, de maneira planejada, justa e consistente, visando uma excelente qualidade de vida para a atual e as futuras gerações, capazes de compatibilizar proteção ambiental, crescimento econômico e justiça social.

O Estatuto da Cidade (Lei 10.257/2001) traz aos Municípios novos meios para proteção do patrimônio histórico, dando à propriedade urbana e à cidade como um todo uma função social, com o objetivo de melhoria da qualidade do meio ambiente urbano, em todas as suas dimensões. Nas palavras de Santin, trata-se de um novo "[...] suporte jurídico dos municípios que se propõem a enfrentar os problemas das cidades, dentre eles [...] a proteção do patrimônio histórico, cultural, paisagístico e ambiental municipal". Entre os novos instrumentos de política urbana ali previstos com esta finalidade estão a outorga onerosa do direito de construir, a transferência do direito de construir e as operações urbanas consorciadas (SANTIN, 2013.)

Proteger um bem cultural significa impedir que ele desapareça, mantendo-o preservado para as gerações futuras. Este Decreto-Lei é o primeiro instrumento legal de proteção do Patrimônio Cultural Brasileiro e nas Américas e seus preceitos fundamentais se mantêm atuais e em uso até os nossos dias. Define o Patrimônio Cultural Brasileiro como "conjunto de bens móveis e imóveis existentes no País e cuja conservação é de interesse público, quer por sua vinculação a fatos memoráveis da história do Brasil, quer por seu excepcional valor arqueológico ou etnográfico, bibliográfico ou artístico". A palavra tombo, significando registro, começou a ser empregada pelo Arquivo Nacional Português, fundado por D. Fernando, em 1375, e originalmente instalado em uma das torres da muralha que protegia a cidade de Lisboa. Com o passar do tempo, o local passou a ser chamado de Torre do Tombo. Ali eram guardados os livros de registros especiais ou livros do tombo. No Brasil, como uma deferência, o Decreto-Lei adotou tais expressões para que todo o bem material passível de acautelamento, por meio do ato administrativo do tombamento, seja inscrito no Livro do Tombo correspondente. A lista de bens culturais inscritos nos Livros do Tombo é a versão mais recente sistematizada e publicada sobre os bens móveis e imóveis tombados pelo Iphan." (IPHAN, 2016) 
Por meio destes novos instrumentos de política urbana viabiliza-se a revitalização de áreas de interesse histórico e artístico degradadas das cidades brasileiras. (ver artigos 28 a 35 da Lei 10.257/2001). Para tanto conta-se com recursos da iniciativa privada em parceria com o poder público, assim como concede a possibilidade de o proprietário de imóveis de interesse ambiental, histórico, cultural ou paisagístico em vender ou transferir onerosamente o direito de construir que possui naquela área para outra área de sua propriedade ou não, recebendo assim uma contrapartida para compensar as limitações de seu direito de propriedade em prol do interesse coletivo.

Assim, o Estatuto da Cidade abre uma oportunidade nova e desafiante para os cidadãos e para o administrador local: de intervir, de modo concreto, sobre o território, na perspectiva de construir cidades mais justas, belas, capazes de valorizar sua história, sua cultura e seu meioambiente natural e artificial. Faz com que o proprietário de imóvel com valor histórico, paisagístico, cultural ou artístico não tenha apenas ônus de uma limitação em sua propriedade, característica do processo de tombamento, mas que também possa auferir de alguns "bônus", como a possibilidade de retorno financeiro pela venda do solo criado, gerada pela outorga ou transferência do direito de construir.

Com novos instrumentos de política urbana o Estatuto da Cidade procura evitar: usos incompatíveis e inconvenientes da propriedade; o parcelamento do solo, a edificação ou o uso excessivo ou inadequado em relação à infraestrutura urbana; a instalação ou empreendimentos que possam funcionar como polos geradores de tráfego sem previsão da infraestrutura correspondente; a retenção especulativa de imóveis, que resulte na sua subtilização ou não utilização; a deterioração das áreas urbanizadas; a degradação do patrimônio histórico, cultural, artístico e paisagístico do Município e, por fim, a poluição e a degradação ambiental (art. 2, inciso VI da Lei 10.257/2001). O que se pretende, com o Estatuto da Cidade, é justamente garantir o desenvolvimento qualitativo, em que, mesmo com o crescimento da população e o desenvolvimento econômico do município não haja comprometimento da memória e da qualidade de vida e do meio ambiente das atuais e futuras gerações.

Outra grande novidade trazida pelo Estatuto da Cidade é a gestão democrática municipal. ${ }^{6}$ De acordo com as diretrizes expressas no Estatuto, os Planos Diretores Municipais devem contar necessariamente com a participação da população e de associações representativas dos vários segmentos econômicos e sociais, não apenas durante o processo de

\footnotetext{
${ }^{6}$ Para maior aprofundamento sobre gestão democrática municipal no Estatuto da Cidade ver: (SANTIN; FINAMORE, 2007); (SANTIN, 2005) e (TOAZZA; SANTIN, 2014).
} 
elaboração e votação, mas, sobretudo, na implementação e gestão das decisões ali definidas. Assim, mais do que um documento técnico, normalmente hermético ou genérico, distante dos conflitos reais que caracterizam a cidade, o Plano Diretor passa a ser um espaço de debate dos cidadãos e de definição de opções, conscientes e negociadas, por uma estratégia de intervenção no território (arts. 39 e seguintes da Lei 10.257/01).

O direito à participação cidadã no planejamento urbano é citado inicialmente no capítulo I (das diretrizes gerais), em seu art. $2^{\circ}$, inciso II, no que tange à: "gestão democrática por meio da participação da população e de associações representativas dos vários segmentos da comunidade na formulação, execução e acompanhamento de planos, programas e projetos de desenvolvimento urbano". A norma citada determina a observância expressa pelos governantes municipais de convidar (aqui no sentido de publicidade e de transparência), receber e ouvir a comunidade em todo assunto que lhe for de interesse, e em especial na definição do macrozoneamento de seu Município, o qual deve se dar de maneira sustentável, para as presentes e futuras gerações.

Também citado no mesmo artigo 2., sob o inciso XIII, fala-se da obrigatoriedade de "audiência do Poder Público municipal e da população interessada nos processos de implantação de empreendimentos ou atividades com efeitos potencialmente negativos sobre o meio ambiente natural ou construído, o conforto ou a segurança da população." Trata-se de dispositivos que traduzem formas de inclusão da população nos assuntos que the são inerentes, a qual passa a ser coparticipante da definição das políticas públicas e das leis sobre meio ambiente artificial da cidade em que ela vive.

O tema da participação é citado também no capítulo III (do plano diretor), em seu artigo 40, parágrafo $4^{\circ}$, inciso I, que dispõe que no processo legislativo de elaboração do Plano Diretor Municipal deverá ser garantida: "a promoção de audiências públicas e debates com a participação da população e de associações representativas dos vários segmentos da comunidade"; no inciso II, "a publicidade quanto aos documentos e informações produzidos" e no inciso III, "o acesso a qualquer interessado aos documentos e informações produzidos". Veja-se que aqui a lei insere mais um procedimento no processo legislativo de edição do Plano Diretor Municipal, qual seja, a promoção das audiências públicas, as quais devem inserir debates com ampla participação da sociedade civil, tanto individual quanto por meio de associações representativas dos diversos segmentos sociais, sob pena de nulidade formal do Plano Diretor, por vício formal em seu processo legislativo. 
Por sua vez, o Estatuto da Cidade dedica um capítulo inteiro para regular a gestão democrática municipal, que é o seu capítulo IV. No art. 43, indica os instrumentos capazes de proporcionar esta participação: a) órgãos colegiados de política urbana, nos níveis nacional, estadual e municipal; b) debates, audiências e consultas públicas; c) conferências sobre assuntos de interesse urbano, nos níveis nacional, estadual e municipal; d) iniciativa popular de projeto de lei e de planos, programas e projetos de desenvolvimento urbano.

No seu artigo 44, o Estatuto da Cidade fala da gestão orçamentária participativa, a qual "inclui a realização de debates, audiências e consultas públicas sobre propostas do plano plurianual, da lei de diretrizes orçamentárias e do orçamento anual, como condição obrigatória para sua aprovação pela Câmara Municipal". Veja-se que aqui novamente o Estatuto da Cidade insere mais uma etapa no processo legislativo de edição das leis orçamentárias municipais, qual seja, a promoção de debates, audiências e consultas públicas, sob pena de nulidade por vício formal no processo legislativo de elaboração das leis orçamentárias em âmbito municipal.

E no derradeiro artigo deste importante capítulo sobre gestão democrática municipal, de número 45, dita que "os organismos gestores das regiões metropolitanas e aglomerações urbanas incluirão obrigatória e significativa participação da população e de associações representativas dos vários segmentos da comunidade, de modo a garantir o controle direto de suas atividades e o pleno exercício da cidadania".

Ou seja, o novo diploma legal guia-se por uma nova forma de governar as cidades, capaz de aliar democracia representativa com democracia participativa, a qual se dará por meio da participação da população e de associações representativas de vários segmentos da comunidade na execução e acompanhamento de programas e projetos de desenvolvimento urbano (art. 2o, II e Capítulo IV da Lei 10.257/01). Objetiva-se neste processo compartilhado de gestão entre sociedade civil e sociedade política otimizar as decisões sobre leis e políticas públicas municipais, com vistas a atingir o desenvolvimento sustentável das cidades, as quais devem crescer economicamente, mas com justiça social e proteção ao patrimônio ambiental, histórico, cultural, paisagístico e artístico.

É no Município que o cidadão exerce seu papel, estabelecendo suas atividades de lazer, educação, trabalho, convivência, direitos e deveres. O Município tem a sua base territorial, com peculiaridades e características próprias: geográficas, hidrográficas, ambientais. Cabe ao governo municipal, em conjunto com os seus munícipes, as entidades da sociedade civil e os empreendedores econômicos, traçarem as metas para um ordenamento do espaço físico da 
cidade, de modo com a que a mesma possa cumprir a sua função social e atender às normas gerais ditadas pelo Estatuto da Cidade tanto para atuais quanto às futuras gerações.

Assim, é correto afirmar que muitos são os dispositivos relacionados à preservação do patrimônio histórico, como já descrito aqui, bem como a possibilidade legítima de participação ativa da população neste processo. Contudo, os instrumentos legais devem ser trazidos à luz da sociedade para a consagração da sua existência. É dessa forma que se possibilita aos cidadãos comuns a tomada de decisão sobre os temas que lhes são pertinentes. A busca de sentido para a existência, coletiva ou não, leva o indivíduo ao encontro de suas origens, ao seu referencial, e uma sociedade deve buscar suas referências em um passado comum. E, nesse sentido, a preservação do patrimônio histórico material mostra-se imperante e fundamental.

\section{SOCIEDADE E EDUCAÇÃO: O RESGATE DO PODER LOCAL}

Sobre a questão da educação, sabe-se que o processo de conscientização da sociedade para a importância da preservação do bem público é, em regra geral, demasiadamente lento, levando-se em conta sua subjetividade. Ainda assim, para viabilizar a introdução da cultura de valorização do bem de importância histórica é fundamental que seu encaminhamento tenha como ponto de partida os bancos escolares. Horta esclarece acerca do papel da educação como meio de instigar a consciência nos indivíduos sobre suas relações com o espaço de vivência e o universo de referências que o envolve (HORTA et al, 1999), em suas palavras:

O trabalho da educação patrimonial é o de possibilitar a investigação das relações e das emoções humanas cristalizadas ou vivas nos bens culturais, e de ensinar às pessoas a aprender como fazer o mesmo. Pelo questionamento ativo dessas evidências podemos conhecer melhor as relações do homem com seu meio ambiente e com os seus semelhantes, as relações entre o cultural e o natural, a interação entre os indivíduos e os seus locais e circunstâncias de vida. O passado, assim desmistificado, ilumina, de maneira positiva ou às vezes cruel. (HORTA et al, 1999)

Desse modo, é possível verificar a importância da educação patrimonial como instrumento de mediação, para que os indivíduos interajam com o meio em que vivem e, também, para incitar e fundamentar organizações comunitárias, capazes de aproximar o cidadão da vida pública de sua cidade, de sua região, consolidando a prática do exercício da democracia participativa. Para tanto é fundamental que a população entenda sua relação com o patrimônio existente em seu ambiente de vivência e o perceba como algo pertencente a ela. É a partir do processo educativo que se constata a pulverização das ideias para dentro das casas, para as famílias e do meio social, instituindo-se de forma didática e emocional uma cultura patrimonial, evitando imposições 
educacionais ortodoxas. Da mesma forma que tem se conseguido imprimir a consciência ecológica e de preservação do meio-ambiente em todas as esferas do ensino formal (desde educação infantil, ensino fundamental, médio e superior), onde os resultados, embora pareçam acanhados, já são, de fato, significativos, também é possível se concretizar essa conscientização em outras realidades relevantes ao processo formador do cidadão.

Sobre a temática do processo de transmissão da cultura, Machado (2012, p. 37) comenta que se idealiza "cultura como prática educativa" para tomar como referência o processo em que os indivíduos interagem com diferentes grupos sociais, em lugares e tempos distintos. Na gênese desse processo transmitem-se aos componentes mais jovens os "elementos culturais" de seus grupos sociais, inclusive com o objetivo de conservá-los, passando-os para as gerações futuras.

A educação patrimonial deve ser incentivada pelo Estado, e aliados a este recurso devem estar conjugados os códigos de posturas municipais, atualmente caracterizados pelos novos Planos Diretores, balizados a partir da regulação federal imposta pelo Estatuto da Cidade. É de fundamental importância que a sociedade participe dessas decisões, exercendo, assim, o Poder Local, que segundo Santin (2007, p. 75) desenvolve-se a partir da união das forças da sociedade civil e do Estado, compartilhando as decisões de seus problemas. Nas palavras de Ribeiro e Pontual "a promoção da participação das entidades de representação das camadas populares na elaboração dos planos diretores pode ser não apenas um instrumento de pressão para que expressem seus interesses, mas também um importante momento de construção desse projeto." (RIBEIRO; PONTUAL, 2009).

Nesse sentido, em um Estado Democrático de Direito o Poder Local alia dois elementos: descentralização e participação popular no exercício do poder político. Apresenta-se como um novo paradigma de exercício do poder político, fundado na emancipação de uma nova cidadania, a qual rompe as fronteiras burocráticas que separam o Estado do cidadão e recupera o controle do cidadão no seu Município, mediante a reconstrução de uma esfera pública comunitária e democrática. Conjugam-se práticas de democracia participativa à representação tradicional, em que os cidadãos, agindo de forma conjunta com o poder público, passam a ser responsáveis pelo seu destino e pelo destino de toda a sociedade.

A conceituação de Poder Local mostra-se mais abrangente que a de governo local, pois pode abranger tanto o Município quanto algo mais amplo, como uma região; ou ainda algo mais restrito, como um bairro ou vila. Seu caráter é mais sociológico, em contraponto à noção de governo local, que tem um enfoque mais próximo do Direito Administrativo ou Constitucional. Nesse sentido, Gohn afirma que, a partir dos anos 90 o 
Poder Local passou a ser identificado não somente com a sede político-administrativa do governo municipal, ou seja, as sedes urbanas, cidades ou Municípios, mas também com as formas de participação e organizações populares florescentes, desenvolvidas em especial por redes societárias, unindo uma dimensão sociológica àquela geográfica-espacial. Alguns o identificam, inclusive, com empowerment, capacitando a comunidade, em conjunto com o poder público, a produzir políticas autossustentáveis de desenvolvimento em âmbito local (GOHN, 2001, p. 34-35).

A alienação do povo e a resistência em participar da gestão do objeto público não são mais que um reflexo da falta de confiança na classe política. A discussão sobre o tema da participação popular está em pauta no contexto atual (SANTIN, 2007, p. 77). O Brasil vive um momento em que a sua população acorda para uma transformação comportamental. A sociedade brasileira está a tomar consciência de que existem meios para exercer seu papel de cidadão, não só para reivindicar direitos individuais, mas também direitos comuns a toda população, como aqui se defende o direito à preservação do patrimônio histórico material. E todo esse processo deve ser potencializado a partir do processo educativo.

\section{CONCLUSÃO}

O processo evolutivo da civilização está intrinsicamente ligado ao processo evolutivo da cidade. O planejamento urbano sempre esteve atrelado a melhor adequação das comunidades ao meio em que elas estão inseridas. O urbanismo nasce da necessidade de se ordenar os espaços, mas principalmente, as atividades que inter-relacionam os indivíduos, o que normalmente está associado às aglomerações constituídas pelo crescimento desordenado das ações humanas e do aumento em progressão geométrica da população, a qual enfrenta a dialética persistente da atuação dos tempos.

A cidade continua a crescer e ganhar novos limites e traçados. Nesse sentido, a problemática urbana precisa ser atendida não apenas para a satisfação de um determinado grupo de pessoas, ao contrário do que vinha sendo recorrente até o século XIX, mas orientada para o benefício do maior número de cidadãos possível.

A Carta de Atenas já advertia para as questões básicas de que um indivíduo oriundo de qualquer comunidade necessita em uma cidade, que é habitar, circular, trabalhar e recrear-se (LE CORBUSIER, 1993). Apesar de muitas cidades ainda não contemplarem esses aspectos, o entendimento acerca das reais necessidades de integrar todos os indivíduos em relação ao espaço urbano de maneira justa e igualitária é algo premente. Entretanto, o ato de zonear fisicamente 
uma cidade, estipulando índices e modificando gabaritos para adaptar esse organismo que é dinâmico e imprevisível, não é suficiente. É fundamental, na medida do possível, integrar de forma harmoniosa a diversidade multidisciplinar que compõe o espaço urbano e torná-lo acessível a todos, indiscriminadamente.

Sendo assim, o patrimônio histórico, cultural, paisagístico e ambiental é direito de todos e, para isso, deve ser portador da história, da cultura, da memória de todos os grupos sociais. O valor que compete a um patrimônio é o valor que a ele se atribui. Se a sociedade não atribui valor para aspectos importantes de sua formação e memória, então provavelmente sua trajetória estará vazio de significados, tornando sua vivência efêmera, sedimentada em bases frágeis e com expectativas precárias de futuro, o que gera insegurança, pessimismo, falta de identidade e de engajamento com o coletivo.

Está muito claro que dispositivos legais para preservação do patrimônio são indispensáveis, caso contrário não haveria um esforço tão intenso e árduo em prol do tema. Neste momento, o que compete à sociedade é cobrar e fiscalizar a efetivação dos dispositivos constitucionais e infraconstitucionais aqui estudados, destinados a proteger o patrimônio. Trata-se do entendimento entre os agentes responsáveis pela coordenação de atividades ligadas à especulação imobiliária e à construção civil em conjunto com os organismos da sociedade civil de preservação ambiental, para fazer valer seus deveres e direitos.

Estes são os preliminares básicos para se ter uma aproximação mais amigável com os temas relacionados ao patrimônio histórico material e consequentemente, ao tombamento. Já se observam progressos em torno destas discussões e, gradativamente, estes temas estão sendo absorvidos pela sociedade, que, de fato, ainda necessita de muita informação e esclarecimento sobre a importância do patrimônio histórico e cultural e as possíveis contrapartidas para sua conservação. Foram dados os primeiros passos para a descoberta da consciência patrimonial, da gestão democrática municipal e da elaboração participativa das leis e políticas urbanas relativas ao meio ambiente urbano. Resta consolidá-los para as presentes e futuras gerações.

\section{REFERÊNCIAS BIBLIOGRÁFICAS}

BRASIL. Estatuto da Cidade. Lei 10.257, de 10 de julho de 2001. - 3a Ed. - Brasília: Câmara dos Deputados, Edições Câmara, 2010.

CHOAY, Françoise. A alegoria do patrimônio. São Paulo: Estação Liberdade/UNESP, 2001. 
FAZIO, Michael; MOFFET, Marian; WODEHAOUSE, Lawrence. A história da arquitetura mundial. Porto Alegre: AMGH, 2011.

FONSECA, Maria Cecília Londres. O patrimônio em processo: trajetória da política federal de preservação no Brasil. 2a edição, Rio de Janeiro: Editora UFRJ; MINC - IPHAN, 2005.

GOHN, Maria da Glória. Educação não-formal e cultura política. 2.ed. São Paulo: Cortez, 2001.

GONSALES, Célia Helena Castro. Cidade moderna sobre cidade tradicional: movimento e expansão - parte 2. Arquitextos, São Paulo, ano 05, n. 059.04, Vitruvius, abr. 2005. Disponível em: http://www.vitruvius.com.br/revistas/read/arquitextos/05.059/473. Acesso em 06 jan. 2016.

HAROUEL, Jean-Louis. História do Urbanismo. Campinas, SP. Papirus, 1990.

HORTA, Maria de Lourdes Parreira; GRUNBERG, Evelina; MONTEIRO, Adriane Queiroz. Guia básico de educação patrimonial. Brasília: IPHAN: Museu Imperial, 1999.

INSTITUTO DO PATRIMÔNIO HISTÓRICO E ARTÍSTICO NACIONAL (IPHAN). Portaria no 127 de 30/04/2009. Estabelece a chancela da Paisagem Cultural Brasileira. Disponível em: https://iphanparana.wordpress.com/iphanparana/legislacao/legislacao-do-patrimoniomaterial/portaria-no-127-de-30-de-abril-de-2009/. Acesso em 23 mar. 2016.

INSTITUTO DO PATRIMÔNIO HISTÓRICO E ARTÍSTICO NACIONAL (IPHAN). Tombamento. Disponível em: $\quad$ https://iphanparana.wordpress.com/iphanparana/legislacao/legislacao-do-patrimoniomaterial/portaria-no-127-de-30-de-abril-de-2009/. Acesso em 23 mar. 2016.

LE CORBUSIER. Carta de Atenas. Tradução de Rebeca Scherer. São Paulo: HUCITEC, EDUSP, 1993.

LE CORBUSIER. Planejamento Urbano. São Paulo: Perspectiva, 2000.

MACHADO, Ironita Policarpo. Metodologia, Patrimônio e Ensino. In: ZANOTTO, Gizele; MACHADO, Ironita Policarpo (Orgs.). Momento Patrimônio. v. I. Passo Fundo: Berthier, 2012. p. 35-58.

PIÑÓN, Helio. Teoria do projeto. Traduzido por Edson Mahfuz. Porto Alegre: Livraria do Arquiteto, 2006.

RIBEIRO, Cecilia; PONTUAL, Virgínia. A reforma urbana nos primeiros anos da década de 1960. Arquitextos, São Paulo, ano 10, n. 109.07, Vitruvius, jun. 2009 Disponível em: <http://www.vitruvius.com.br/revistas/read/arquitextos/10.109/50.>. Acesso em 06 jan. 2016.

SANTIN, Janaína Rigo. A Gestão Democrática Municipal no Estatuto da Cidade e a Teoria do Discurso Habermasiana. Revista da Faculdade de Direito. Universidade Federal do Paraná, CuritibaPR, v. 42, p. 121-131, 2005.

SANTIN, Janaína Rigo. Estatuto da Cidade e Instrumentos de Política Urbana para Valorização do Patrimônio Histórico, Cultural, Paisagístico e Ambiental. Revista de Direito Ambiental, v. 70, abr./jun. 2013. p. 195-214. 
SANTIN, Janaína Rigo. O Tratamento Histórico do Poder Local no Brasil e a Gestão Democrática Municipal. Estudos Jurídicos (UNISINOS), v. 40, p. 72-78, 2007.

SANTIN, Janaína Rigo; FINAMORE, E. B. . A Gestão Democrática Municipal e o Papel dos Conselhos em Passo Fundo. História. Debates e Tendências (Passo Fundo), v. 7, p. 204-225, 2007.

SILVEIRA, Carlos Eduardo; MEDAGLIA, Juliana (Orgs.). Desenvolvimento Turístico em Cidades Históricas: o caso de Diamantina/MG. Diamantina: UFVJM, 2014.

TOAZZA, Vinícius Francisco; SANTIN, Janaína Rigo. A Evolução do Municipalismo Brasileiro e a Gestão Democrática Municipal. In: Antonio Carlos Wolkmer; Ricardo Marcelo Fonseca; Gustavo Silveira Siqueira. (Org.). História do Direito. 1ed.Florianópolis-SC: CONPEDI, 2014, v. 1, p. 305-329. Disponível em: http://www.publicadireito.com.br/artigos/?cod=a5460fe6c23289fd.

ZANCHETTA, Ricardo. Da Pintura de Leon Battista Alberti: comentário e tradução do primeiro livro. Dissertação de Mestrado em Filosofia, Letras e Ciências Humanas da Universidade de São Paulo. Departamento de Filosofia. São Paulo, 2014. Disponível em: http://www.teses.usp.br/teses/disponiveis/8/8133/tde-16102014-101330/pt-br.php. Acesso em 22 set. 2015.

Trabalho enviado em 07 de janeiro de 2016.

Aceito em 27 de março de 2016. 